\title{
Expression of different religions and castes in determining food habits of adolescents
}

\section{Albha Tiwari}

Author for correspondence:

\section{Albha Tiwari}

Department of Home Science,

V.R.G. Girls Postgraduate

College, Morar, Gwalior (M.P)

India

Email : albha23@rediffmail.com

Received: 03.06.2019; Revised: 28.10.2019; Accepted: 12.11 .2019

ABSTRACT : Differences in adolescent's food habits were observed in India as a consequence of religious and caste. Hindu caste had nutritious diet predominantly; whereas, boys of Sikh and Muslim religion had fast food. In 16-18 yrs age, boys and girls of Hindu caste had nutritious diet and fast food habit in boys and girls of Muslim and Sikh religion predominantly. Highly significant differences were found among nutritional and fast food habits in girls in both age group (13-15 and 16-18 yrs). Among high caste boys' and girl adolescents of 13-15 and 16-18 yrs showed maximum consumption of fast food than nutritious food. Whereas, in backward castes; adolescent boys (13-15 yrs) predominantly to have nutritious food as compare to other age group. In schedule caste group, adolescent boys' and girls' of all age group intake fast food more frequently than nutritious food. In other castes, fast food intake was more than nutritious food among boys adolescents of 13-15 and 16-18 yrs age group. The t-test indicates that there is non-significant difference between nutritional and fast food habit of boy adolescents of 13-15 yrs.

KEY WORDS: Adolescents, Food habits, Age, Religion, Caste

- HOW TO CITE THIS PAPER : Tiwari, Albha (2019). Expression of different religions and castes in determining food habits of adolescents. Asian J. Home Sci., 14 (2) : 398-402, DOI: 10.15740/HAS/AJHS/ 14.2/398-402. Copyright@ 2019: Hind Agri-Horticultural Society. 